\title{
KERAGAAN LEMBAGA KEUANGAN DI KECAMATAN PANGALENGAN, KABUPATEN BANDUNG
}

\author{
THE PERFORMANCE OF FINANCIAL INSTITUTIONS \\ IN PANGALENGAN SUBDISTRICT, BANDUNG DISTRICT
}

\author{
Annida Aisah*, Eliana Wulandari \\ Fakultas Pertanian, Universitas Padjadjaran \\ *E-mail: annidaaisah20@gmail.com \\ (Diterima 27-12-2019; Disetujui 16-01-2019)
}

\begin{abstract}
ABSTRAK
Kecamatan Pangalengan merupakan salah satu sentra produksi kentang terbesar di Jawa Barat. Kurangnya modal yang dimiliki petani dan tidak menentunya hasil panen serta harga input produksi yang sangat tinggi menyebabkan petani memerlukan pembiayaan dari lembaga keuangan, baik lembaga keuangan bank maupun lembaga keuangan non-bank. Sektor pertanian merupakan sektor yang berisiko tinggi, sehingga lembaga keuangan terutama bank kurang tertarik untuk membiayai usaha pertanian. Penelitian ini menggunakan analisis deskriptif yang menggunakan data primer dan data sekunder. Hasil penelitian menunjukkan bahwa sulitnya akses petani terhadap lembaga keuangan disebabkan oleh persyaratan-persyaratan yang belum sesuai dengan kemampuan beberapa petani di Kecamatan Pangalengan.
\end{abstract}

Kata kunci: Lembaga keuangan, Petani, Kecamatan Pangalengan

\section{ABSTRACT}

Pangalengan Sub District is one of the largest potato production centers in West Java. Lack of capital of farmers, uncertain yields and very high production input prices cause farmers need to access credit from financial institutions, both bank and non-bank financial institutions. Agriculture sector is a high-risk sector, financial institutions especially banks are less interested in financing the agricultural business. This research applies descriptive analysis using primary and secondary data. The results showed that the difficulty of farmers' access to financial institutions was due to requirements that could not be fulfilled by some farmers in Pangalengan Sub District.

Keywords: Financial institutions, Farmers, Pangalengan Sub District

\section{PENDAHULUAN}

Kecamatan Pangalengan merupakan salah satu sentra produksi kentang terbesar di Jawa Barat. Menurut Dinas Pertanian Kabupaten Bandung, para petani hortikultura di Pangalengan mengeluh karena harga input produksi yang meningkat sedangkan modal yang dimiliki petani sedikit dan hasil panen yang tidak menentu, sehingga para petani memerlukan kredit dari lembaga keuangan sebagai bantuan modal usahataninya $^{1)}$.

Lembaga pembiyaan merupakan badan usaha yang melakukan kegiatan pembiayaan dalam bentuk penyediaan dana atau barang modal dengan tidak menarik dana secara langsung dari 
masyarakat (Pasal 1 Ayat 2 Keppres No.61 Tahun 1988 tentang Lembaga Keuangan). Menurut Geminastiti dan Nurlita (2016), lembaga keuangan terbagi menjadi dua, yaitu lembaga keuangan bank dan lembaga keuangan non bank. Menurut Undang-Undang No. 10 Tahun 1998 Pasal 1 Ayat 2, bank adalah badan usaha yang menghimpun dana dari masyarakat dalam bentuk simpanan dan menyalurkannya kepada masyarakat dalam bentuk kredit dan atau bentukbentuk lainnya dalam rangka meningkatkan taraf hidup rakyat banyak. Berdasarkan Keppres No.61 Tahun 1988 Pasal 2 Ayat 1, Lembaga Pembiayaan melakukan kegiatan yang meliputi antara lain bidang usaha: (a) Sewa Guna Usaha, (b) Modal Ventura, (c) Perdagangan Surat Berharga, (d) Anjak Piutang, (e) Usaha Kartu Kredit, dan (f) Pembiayaan Konsumen. Adapun jenis bank menurut fungsinya terbagi menjadi dua yaitu bank umum dan bank perkreditan rakyat, sedangkan berdasarkan kegiatan usahanya, bank terbagi menjadi dua yaitu bank konvensional dan bank syariah (Geminastiti dan Nella, 2016).

Lembaga keuangan non bank merupakan lembaga yang bergerak di bidang keuangan secara langsung maupun tidak langsung dalam menghimpun dana dari masyarakat dan menyalurkannya kembali kepada masyarakat (Nurhadi, 2013). Adapun fungsi dari lembaga keuangan non bank menurut Nurhadi (2013) adalah untuk memperlancar penyaluran barang, memperbanyak lapangan kerja, dan meningkatkan produktivitas barang dan jasa. Jenis-jenis lembaga keuangan non bank menurut Wiwoho (2014) adalah : (1) Perusahaan Asuransi, (2) Dana Pensiun, (3) Koperasi Simpan Pinjam, (4) Pasar Modal, (5) Perusahaan Anjak Piutang, (6) Perusahaan Modal Ventura, (7) Perusahaan Pegadaian, (8) Perusahaan Kartu Kredit, (9) Perusahaan Sewa Guna Usaha, (10) Pasar Uang, dan (11) Perusahaan Pembiayaan Infrastruktur.

Tabel 1. Perkembangan Jumlah Kantor Cabang Bank Umum Berdasarkan Lokasi Bank di Indonesia (Unit)

\begin{tabular}{lccc}
\hline \multicolumn{1}{c}{ Lokasi } & 2017 & 2018 & 2019 \\
\hline DKI Jakarta & 544 & 528 & 510 \\
Jawa Barat & 413 & 415 & 412 \\
Jawa Timur & 432 & 430 & 428 \\
Lainnya & 2.319 & 2.336 & 2.347 \\
\hline Total & 3.708 & 3.709 & 3.697 \\
\hline Sumber: Otoritas Jasa Keuangan, 2019
\end{tabular}

Berdasarkan Tabel 1, pada tahun 2017 hingga 2019, perkembangan jumlah kantor cabang bank umum mengalami fluktuasi, dan di tahun 2019 jumlah kantor cabang bank umum mengalami penurunan yang cukup drastis dari tahun sebelumnya. Selama tiga tahun berturut turut, DKI Jakarta menempati posisi 
pertama dengan jumlah kantor cabang bank umum terbanyak, sedangkan Jawa Barat menempati posisi ketiga dengan jumlah kantor cabang bank umum terbanyak di Indonesia.

Tabel 2. Tabel Perkembangan Jumlah Kantor Bank di Jawa Barat Periode 20152017 (Unit)

\begin{tabular}{lccc}
\hline \multicolumn{1}{c}{ Kota / } & 2015 & 2016 & 2017 \\
\hline Kabupaten & 2017 & 773 \\
Kota Bandung & 866 & 794 & 341 \\
Kabupaten & 360 & 352 & \\
Bandung & & & 385 \\
Kota Bekasi & 401 & 395 & 3.448 \\
Lainnya & 3.582 & 3.486 & 5.947 \\
\hline Total & 5.209 & 5.027 & 4.947 \\
\hline
\end{tabular}

Sumber: Kantor Perwakilan Bank Indonesia Provinsi Jawa Barat, 2016-2018

Berdasarkan Tabel 2, pada tahun 2017, jumlah kantor bank di Jawa Barat mengalami penurunan dari tahun 2015 dan 2016. Kota Bandung memiliki jumlah kantor bank terbanyak pertama di Jawa Barat, sedangkan Kabupaten Bandung menempati urutan ketiga setelah Kota Bekasi.

Selain lembaga keuangan bank, juga terdapat lembaga keuangan non bank yang dapat membantu masyarakat dalam mendapatkan bantuan pembiayaan yaitu salah satunya adalah koperasi simpan pinjam. Koperasi simpan pinjam memiliki fungsi untuk melayani masyarakat terutama anggotanya dalam memenuhi keperluannya untuk menyimpan dan meminjam dana. Bank Indonesia (2001) menyatakan bahwa dilihat dari jumlah pinjamannya, (kredit/pembiayaan yang disalurkan), posisi koperasi simpan pinjam dan unit simpan pinjam termasuk dua besar setelah BRI Unit Desa. Perkembangan jumlah koperasi di Indonesia periode 2016-2018 disajikan dalam Tabel 3.

Tabel 3. Perkembangan Jumlah Koperasi di Indonesia Periode 2016-2018 (Unit)

\begin{tabular}{lccc}
\hline \multicolumn{1}{c}{ Provinsi } & 2016 & 2017 & 2018 \\
\hline Jawa Tengah & 25.549 & 21.667 & 13.460 \\
Jawa Timur & 31.980 & 27.683 & 24.024 \\
Jawa Barat & 25.549 & 16.203 & 11.127 \\
Lainnya & 125.117 & 86.621 & 77.732 \\
\hline Total & 208.195 & 152.174 & 126.343 \\
\hline Sumber: Kementerian Koperasi dan Usaha Kecil \\
\multicolumn{4}{c}{ Menengah, 2017-2019 }
\end{tabular}

Adapun perkembangan jumlah koperasi di Indonesia pada Tabel 3, dari tahun 2016 hingga 2018 mengalami penurunan yang sangat drastis. Menurut data dari Dinas Koperasi dan UKM Provinsi Jawa Barat, pada tahun 2018 total koperasi yang berada di Jawa Barat sebanyak 24.727 unit, Koperasi Unit Desa sebanyak 627 unit, dan Koperasi Non KUD sebanyak 24.057 unit.

Menurut Renstra Kementan (2019), sektor pertanian terutama tanaman pangan memiliki kontribusi yang besar terhadap penyedia kebutuhan, penghasil devisa negara, penyedia lapangan pekerjaan dan pendapatan masyarakat. Berdasarkan catatan Badan Pusat Statistik (BPS) pada bulan Februari tahun 2018, pekerjaan penduduk Indonesia 
terbanyak adalah di sektor pertanian. Jumlah tenaga kerja sektor pertanian dan non pertanian di Indonesia pada tahun 2016-2018 disajikan pada Tabel 4.

Tabel 4. Jumlah Tenaga Kerja Sektor Pertanian dan Non Pertanian di Indonesia Periode 2016-2018 (Jiwa)

\begin{tabular}{lccc}
\hline \multicolumn{1}{c}{ Sektor } & 2016 & 2017 & 2018 \\
\hline Pertanian & 35.649 .184 & 36.956 .111 & 35.875 .389 \\
Non & 82.356 .586 & 84.860 .396 & 88.367 .305 \\
Pertanian & & & \\
\hline Total & 118.005 .770 & 121.816 .507 & 124.242 .694 \\
\hline
\end{tabular}

Sumber: Kementerian Pertanian, 2016-2018

Berdasarkan Tabel 4, jumlah tenaga kerja sektor pertanian dan non pertanian di Indonesia periode tahun 2016 hingga 2018 mengalami peningkatan setiap tahunnya, hal ini terjadi karena perkembangan jumlah penduduk di
Indonesia yang setiap tahunnya meningkat.

Dilihat dari Tabel 5, jumlah kredit yang dikucurkan bank pada periode 2016 sampai 2018 mengalami peningkatan dari tahun ke tahunnya, dan kredit yang terbesar yang dikucurkan adalah untuk sektor perdagangan besar dan eceran yaitu Rp. 532.134 miliar. Sedangkan untuk sektor pertanian, perburuan, dan kehutanan, terutama sektor pertanian, lembaga keuangan bank kurang tertarik memberikan kredit karena sektor pertanian merupakan sektor yang beresiko tinggi (Sayaka dan Rivai, 2011).

Tabel 5. Jumlah Kredit yang Dikucurkan Bank Periode 2016-2018 (Rp. Miliar)

\begin{tabular}{lccc}
\multicolumn{1}{c}{ Sektor } & 2016 & 2017 & 2018 \\
\hline Perdagangan Besar dan Eceran & $463.489,3$ & $490.234,9$ & 532.134 \\
\hline Pertanian, Perburuan, dan Kehutanan & $72.603,8$ & $84.224,1$ & $94.274,7$ \\
\hline Industri Pengolahan & $83.719,5$ & $95.523,9$ & $100.281,4$ \\
\hline Lainnya & $258.081,2$ & $281.182,8$ & 310.929 \\
\hline \multicolumn{1}{c}{ Total } & $877.893,8$ & $951.111,7$ & $1.037 .619,1$ \\
\hline
\end{tabular}

Sumber: Bank Indonesia, 2016-2018

Aksesibilitas petani dengan kepemilikan lahan yang sempit untuk mendapatkan kredit pertanian masih terbatas, padahal mayoritas masyarakat pedesaan merupakan petani-petani yang memiliki lahan sempit (Hendriyani dan Karyani, 2015). Selain itu, para petani sulit mengakses kredit ke lembaga keuangan terutama bank dikarenakan prosedurnya yang tidak sesuai dengan karakteristik petani yaitu salah satunya adalah kepemilikan lahan yang nantinya dijadikan sebagai jaminan kepada lembaga keuangan bank (Pattern dan Rosengard, 1991). Oleh sebab itu, keragaan lembaga keuangan terutama di Kecamatan Pangalengan perlu untuk dikaji.

\section{METODE PENELITIAN}

Penelitian ini dilaksanakan di Kecamatan Pangalengan, Kabupaten 
Bandung. Pemilihan lokasi penelitian didasarkan atas Kecamatan Pangalengan merupakan salah satu sentra produksi kentang dimana para petaninya masih mengalami kekurangan modal untuk usahataninya.

Penelitian ini menggunakan analisis deskriptif. Dalam penelitian ini, data yang digunakan adalah data primer yang berasal dari hasil Focus Group Discussion (FGD) yang dilaksanakan di Bandung pada tanggal 18 Juni 2019, hasil survei petani responden dengan menggunakan teknik stratified random sampling di Desa Pulosari dan Desa Pangalengan sebagai sentra produksi kentang di Kecamatan Pangalengan, dan wawancara mendalam pada tanggal 4 September 2019 sampai dengan 15 September 2019 dan data sekunder yang berasal dari data Badan Pusat Statistik, Otoritas Jasa Keuangan (OJK), Bank Indonesia (BI), dan dari Badan Penyuluh Pertanian Kecamatan Pangalengan, Kabupaten Bandung.

\section{HASIL DAN PEMBAHASAN}

Secara garis besar, aksesibilitas petani terhadap kredit ditentukan oleh kondisi sosial ekonomi, karakteristik petani itu sendiri, usaha yang ditekuni, ketersediaan informasi serta karakteristik dari kredit yang akan diakses (Azriani, 2014). Dalam memberikan kredit, bank memiliki kriteria khusus dalam memilih nasabah. Beberapa unsur yang digunakan oleh bank menurut Kasmir (2004) adalah (1) Character yaitu karakter nasabah yang mengajukan kredit, (2) Capacity yaitu kemampuan nasabah untuk melunasi hutangnya, (3) Capital yaitu modal yang dimiliki nasabah, (4) Collateral yaitu jenis barang yang akan dijadikan jaminan oleh nasabah, dan (5) Condition of Economy yaitu kondisi ekonomi usaha yang dibiayai.

\begin{tabular}{lcc} 
Tabel 6. Jumlah Penduduk di & $\begin{array}{c}\text { Kecamatan } \\
\text { Pangalengan } \\
\text { Pendidikan }\end{array}$ & $\begin{array}{c}\text { Kerdasarkan } \\
\text { Berdang }\end{array}$ \\
\hline \multicolumn{1}{c}{ Tingkat Pendidikan } & $\begin{array}{c}\text { Jumlah } \\
\text { (Orang) }\end{array}$ & $\begin{array}{c}\text { Persentase } \\
(\%)\end{array}$ \\
\hline $\begin{array}{l}\text { Belum/Tidak Pernah } \\
\text { Sekolah }\end{array}$ & 7.557 & 5,64 \\
\hline $\begin{array}{l}\text { Tidak Tamat } \\
\text { SD/Sederajat }\end{array}$ & 18.819 & 14,03 \\
\hline SD/Sederajat & 58.400 & 43,54 \\
\hline SLTP/Sederajat & 31.008 & 23,11 \\
\hline SLTA/Sederajat & 15.187 & 11,32 \\
\hline Perguruan Tinggi & 3.186 & 2,37 \\
\hline \multicolumn{1}{c}{ Jumlah } & 134.157 & 100
\end{tabular}

Sumber: Kecamatan Pangalengan Dalam Angka, 2018

Berdasarkan Tabel 6, mayoritas penduduk Kecamatan Pangalengan berpendidikan SD/Sederajat. Dalam aksesibilitas terhadap kredit, karakteristik nasabah menjadi salah satu permasalahan yang membuat petani sulit mendapatkan akses pembiayaan atau kredit. 
Karakteristik nasabah tersebut salah satunya dilihat dari tingkat pendidikan. Rata-rata penduduk di Kecamatan Pangalengan adalah SD/Sederajat. Pendidikan petani yang relatif tinggi akan berpengaruh pada daya nalar yang akan menyebabkan petani berpikir secara dinamis, sedangkan petani dengan pendidikan rendah akan berpikir secara statis dalam pengambilan keputusan (Tomy, 2013). Adapun pekerjaan utama penduduk Kecamatan Pangalengan disajikan dalam Tabel 7.

Tabel 7. Jumlah Penduduk di Kecamatan Pangalengan Pekerjaan

\begin{tabular}{lcc}
\hline \multicolumn{1}{c}{ Pekerjaan } & $\begin{array}{c}\text { Jumlah } \\
\text { (Orang) }\end{array}$ & Persentase (\%) \\
\hline $\begin{array}{l}\text { Petani Tanaman } \\
\text { Bahan Makanan }\end{array}$ & 7.592 & 12,88 \\
\hline Buruh Tani & 21.499 & 36,45 \\
\hline Perdagangan & 8.354 & 14,16 \\
\hline Lainnya & 21.537 & 36,51 \\
\hline \multicolumn{1}{c}{ Total } & 58.982 & 100
\end{tabular}

Sumber: Kecamatan Pangalengan Dalam Angka, 2018

Menurut Kecamatan Pangalengan Dalam Angka Tahun 2018, mayoritas pekerjaan penduduk Kecamatan Pangalengan yang disajikan pada Tabel 7 yaitu buruh tani. Padahal, dalam mendapatkan kredit, jaminan dan kondisi ekonomi usaha yang akan diajukan kredit sangat mempengaruhi. Buruh tani di Kecamatan Pangalengan rata-rata mendapatkan penghasilan yang relatif rendah yaitu sekitar Rp. 25.000,- untuk buruh tani wanita dan Rp. 35.000,- untuk buruh tani laki - laki untuk jam kerja dari pukul 07.00-12.00 WIB, sedangkan apabila buruh tani bekerja sampai pukul 15.00 WIB, maka buruh tani akan mendapatkan upah tambahan. Adapun usaha pertanian merupakan usaha yang risikonya sangat tinggi, dan hasil penjualannya tidak menentu.

Tabel 8. Rata-Rata Kepemilikan Lahan Pertanian di Kecamatan Pangalengan

\begin{tabular}{lcc}
\hline \multicolumn{1}{c}{ Luas Lahan } & $\begin{array}{c}\text { Jumlah } \\
\text { (Orang) }\end{array}$ & $\begin{array}{c}\text { Persentase } \\
(\%)\end{array}$ \\
\hline Tidak memiliki lahan & 1.999 & 63,66 \\
$0-0,5 \mathrm{Ha}$ & 1.113 & 35,44 \\
$0,51-1,0 \mathrm{Ha}$ & 28 & 0,90 \\
$>1,0 \mathrm{Ha}$ & 0 & 0 \\
\hline Total & 3.140 & 100 \\
\hline $\begin{array}{l}\text { Sumber: Rencana Kerja } \\
\text { BPP Pangalengan, 2019 }\end{array}$ & & \\
Penyluhan & Pertanian \\
\end{tabular}

Berdasarkan Tabel 8, petani di Kecamatan Pangalengan banyak yang tidak memiliki lahan, adapun yang memiliki lahan paling banyak sekitar 00,5 Ha dimana menurut Bappenas (2001) artinya petani Kecamatan Pangalengan masuk ke dalam kategori petani skala kecil. Tidak memiliki lahan pertanian merupakan salah satu kendala bagi para petani Pangalengan, karena petani harus membayar sewa lahan dengan harga yang cukup tinggi dengan pendapatan yang seadanya, dan untuk mengakses kredit ke bank pun mereka jadi terhambat karena tidak memiliki jaminan berupa sertifikat 
tanah yang dapat mereka jaminkan kepada lembaga keuangan untuk mendapatkan modal berupa kredit dengan jumlah yang lebih besar.

Tabel 9. Luas Lahan, Produktivitas, dan Nilai Produksi Komoditas Sayuran di Kecamatan Pangalengan Tahun 2018

\begin{tabular}{lccc}
\hline Komoditas & $\begin{array}{c}\text { Luas } \\
\text { Lahan } \\
\text { (Ha) }\end{array}$ & $\begin{array}{c}\text { Produkti- } \\
\text { vitas } \\
\text { (ton/ha) }\end{array}$ & $\begin{array}{c}\text { Nilai } \\
\text { Produksi } \\
\text { (miliar } \\
\text { rupiah) }\end{array}$ \\
\hline Kentang & 2190 & 20,01 & 328,66 \\
Bawang Daun & 229,28 & 38,50 & 220,68 \\
Cabai & 331,75 & 11,43 & 132,71 \\
Lainnya & $7.159,64$ & 250,14 & 126,10 \\
\hline \multicolumn{1}{c}{ Total } & $9.910,67$ & 320,08 & 808,15 \\
\hline
\end{tabular}

Sumber: Profil Kecamatan Pangalengan, 2019

Kecamatan Pangalengan memiliki beraneka ragam komoditas hortikultura, seperti yang disajikan pada Tabel 9, komoditas unggulan Kecamatan Pangalengan adalah kentang. Kentang di Kecamatan Pangalengan memiliki nilai produksi sebesar Rp. 328,66 miliar, sehingga usahatani komoditas kentang perlu untuk dipertahankan. Luasnya lahan untuk komoditas kentang membuat petani harus mengeluarkan modal yang lebih besar untuk membeli input. Tidak semua petani kentang Kecamatan Pangalengan dapat dikatakan mampu karena nilai produksi kentang yang sangat tinggi, seperti yang disajikan pada Tabel 7, penduduk Kecamatan Pangalengan mayoritas merupakan buruh tani yang upah sehari - harinya relatif sedikit, sehingga mereka harus mencari modal tambahan agar bisa membeli input produksi usaha tani kentang.

Selain mendapatkan bantuan modal dari lembaga keuangan bank, petani juga bisa mendapatkan bantuan modal melalui kelompok tani. Kelompok tani dibentuk atas dasar surat keputusan, dimana maksud dan tujuannya adalah sebagai wadah komunikasi antar petani serta petani dengan kelembagaan terkait dalam mendapatkan alat dan mesin pertanian (Wahyuni, 2003). Gabungan kelompok tani di Kecamatan Pangalengan disajikan dalam Tabel 10.

Tabel 10. Gabungan Kelompok Tani

\begin{tabular}{ll}
\multicolumn{1}{c}{ Gapoktan } & \multicolumn{1}{c}{ Kecamatan Pangalengan } \\
\hline Lamajang & Cikondang, Lamajang \\
Bakti Mulya & Lebaksaat, Tribakti \\
Marga Mulya & Narogtog, Margamulya \\
Wargi Setia & Sukamenak Kulon \\
Mulya Agung & Cinangsi, Pulosari \\
Mekar Mulya & Bakir, Margamekar \\
Berkah Mekar & Cipangisikan \\
Saluyu & Wates, Sukaluyu \\
Margaluyu & Puncakraya, Margaluyu \\
Mitra Mukti & Sukamenak Wetan \\
Sukamanah & Cibuntu, Sukamanah \\
Banjarsari & Banjarsari \\
Wanasuka & Wanasuka \\
\hline Sumber: Rencana & Kerja Penyuluhan Pertanian \\
\multicolumn{2}{c}{ BPP Pangalengan, 2019 }
\end{tabular}

Berdasarkan Tabel 10, jumlah Gabungan Kelompok Tani (Gapoktan) Kecamatan Pangalengan berjumlah tiga belas, sesuai dengan jumlah desa yang berada di Kecamatan Pangalengan. Adanya gapoktan tentu saja akan mempermudah para petani untuk 
mendapatkan bantuan modal dari pemerintah, terutama berupa input produksi seperti alat dan mesin pertanian, pupuk bersubsidi, benih kentang, dan sebagainya. Pemerintah akan menyalurkan bantuannya melalui Gapoktan yang nantinya akan disebarkan lagi ke kelompok-kelompok tani yang tergabung dalam gapoktan tersebut.

Selain melalui gapoktan, petani juga dapat mengakses bantuan modal atau kredit ke lembaga keuangan yang ada di Kecamatan Pangalengan. Adapun lembaga keuangan dan lembaga ekonomi yang dapat diakses oleh petani di Kecamatan pangalengan disajikan pada Tabel 11.

Jumlah lembaga keuangan dan lembaga ekonomi di Pangalengan pada tahun 2015-2017 mengalami fluktuasi. Pada tahun 2016, jumlah lembaga keuangan dan lembaga ekonomi di pangalengan mengalami penurunan yang sangat drastis pada koperasi industri kecil dan kerajinan rakyat, koperasi simpan pinjam, dan koperasi non KUD lainnya. Tersedianya lembaga keuangan baik lembaga keuangan bank maupun lembaga keuangan non bank diharapkan dapat membantu petani dalam mendapatkan modal tambahan untuk usaha tani kentangnya, disamping mendapatkan bantuan input dari pemerintah tidak selalu sampai ke tangan petani.

Tabel 11. Lembaga Keuangan dan Lembaga Ekonomi di Kecamatan Pangalengan $\begin{array}{llll}\text { Lembaga } & 2015 & 2016 & 2017\end{array}$ Keuangan (Unit) (Unit) (Unit)

\begin{tabular}{|c|c|c|c|}
\hline Bank Umum & 7 & 9 & 9 \\
\hline $\begin{array}{l}\text { Lembaga } \\
\text { Keuangan Non } \\
\text { Bank }\end{array}$ & 1 & 2 & 2 \\
\hline $\begin{array}{l}\text { Bank Perkreditan } \\
\text { Rakyat (BPR) }\end{array}$ & 2 & 4 & 4 \\
\hline $\begin{array}{l}\text { ATM } \\
\text { Koperasi Unit Desa } \\
\text { (KUD) }\end{array}$ & $\begin{array}{l}3 \\
1\end{array}$ & $\begin{array}{l}3 \\
1\end{array}$ & $\begin{array}{l}4 \\
1\end{array}$ \\
\hline $\begin{array}{l}\text { Koperasi Simpan } \\
\text { Pinjam (Kosipa) }\end{array}$ & 11 & 7 & 7 \\
\hline $\begin{array}{l}\text { Koperasi Industri } \\
\text { Kecil dan } \\
\text { Kerajinan Rakyat } \\
\text { (Kopinkra) }\end{array}$ & 4 & 1 & 1 \\
\hline $\begin{array}{l}\text { Koperasi non KUD } \\
\text { lainnya }\end{array}$ & 15 & 11 & 23 \\
\hline Total & 44 & 38 & 51 \\
\hline
\end{tabular}

Sumber: Kecamatan Pangalengan dalam Angka, 2016-2018

Selain akses terhadap lembaga keuangan bank, petani juga dapat mengakses bantuan modal ke lembaga keuangan non-bank yaitu pedagang/pembeli, kios sarana pertanian, dan kerabat/saudara/tetangga, dan sebagainya. Akses petani Kecamatan Pangalengan terhadap lembaga keuangan pada tahun 2018 disajikan pada Tabel 12.

Tabel 12. Akses Petani Terhadap Lembaga Keuangan Tahun 2018 Lembaga Keuangan Orang

Bank komersil 9

Lembaga Keuangan Mikro (LKM) 10

Pemerintah/koperasi/kelompok tani 2

Pedagang/pembeli 4

Kios sarana pertanian $\quad 18$

Kerabat/saudara/tetangga 9

Total 52

Sumber: Data primer, 2019 (Diolah) 
Pada tahun 2018, petani di Kecamatan Pangalengan mayoritas mengakses bantuan modal ke kios sarana pertanian. Berdasarkan hasil wawancara mendalam, alasan petani mengakses bantuan modal ke kios sarana pertanian adalah tidak ada persyaratan dan bunga yang tinggi, serta letaknya yang dekat dengan rumah dan kebun petani sehingga mudah untuk diakses. Pemberian bantuan modal berupa input hanya didasarkan atas kepercayaan dan hubungan pribadi antara pemilik kios dengan petani yang mengakses modal.

\section{KESIMPULAN DAN SARAN}

Dalam mendapatkan bantuan dari lembaga keuangan dalam bentuk kredit maupun input pertanian tidak mudah. Para petani dihadapkan dengan persyaratan-persyaratan pengajuan yang belum sesuai dengan kemampuan beberapa petani di Kecamatan Pangalengan. Adapun persyaratan yang membuat petani kesulitan mengakses ke lembaga keuangan bank adalah penyerahan agunan (jaminan) dan tingginya suku bunga yang ditentukan oleh lembaga keuangan bank.

Oleh karena itu, petani lebih memilih mengakses kredit ke bandar atau pembeli hasil panennya, meminjam uang kepada keluarganya, meminjam obat ke toko obat maupun toko pupuk yang kemudian dibayar setelah panen. Meskipun hasil panen yang didapatkan lebih kecil jika meminjam ke bandar, tetapi petani tetap mengaksesnya karena tidak ada persyaratan tertentu untuk mengakses ke bandar. Bandar, keluarga, toko obat, dan toko pupuk memberikan pembiayaan kepada petani atas dasar kepercayaan dan hubungan pribadi.

\section{DAFTAR PUSTAKA}

Azriani Z. (2014). Aksesibilitas dan partisipasi indunstri kecil dan rumahtangga pada sumber pembiayaan dan pengaruhnya terhadap kinerja usaha dan kesejahteraan rumahtangga di Kabupaten Bogor Jawa Barat [disertasi]. Bogor: Sekolah Program Pascasarjana, Institut Pertanian Bogor.

Badan Pusat Statistik. (2016). Jawa Barat Dalam Angka tahun 2016. BPS. Kabupaten Bandung.

Badan Pusat Statistik. (2017). Jawa Barat Dalam Angka tahun 2017. BPS. Kabupaten Bandung.

Badan Pusat Statistik. (2018). Jawa Barat Dalam Angka tahun 2018. BPS. Kabupaten Bandung.

Badan Pusat Statistik. (2018). Kecamatan Pangalengan Dalam Angka tahun 2018. BPS. Kabupaten Bandung.Badan Pusat Statistik. (2019). Profil Kecamatan Pangalengan Tahun 2019. BPS. Kabupaten Bandung.

Badan Pusat Statistik. (2019). Penduduk 15 Tahun Ke Atas yang Bekerja menurut Lapangan Pekerjaan 
Utama 1986-2018. diakses pada 30 November 2019 melalui https://www.bps.go.id/statictable/2 009/04/16/970/penduduk-15-tahunke-atas-yang-bekerja-menurutlapangan-pekerjaan-utama-1986--2018.html.

Bank Indonesia. (2019). Perkembangan Kredit UMKM September 2018. diakses pada Hari Senin, 30 Oktober 2019 melalui https://www.bi.go.id/id/umkm/kred it/data/Pages/Data-Kredit-UMKMSeptember-2018--.aspx.

Endang \& Yeyet. (2019). Rencana Kerja Penyuluhan Pertanian BPP Pangalengan, 2019. Dinas Pertanian Kabupaten Bandung, Provinsi Jawa Barat.

Bappenas. (2001). Proyeksi Penduduk, Angkatan Kerja, Tenaga Kerja, dan Peran Serikat Pekerja dalam Peningkatan Kesejahteraan.

Geminastiti, K. \& Nella N. (2016). Ekonomi Untuk Siswa SMA/MA Kelas X. Penerbit Yrama Widya Bandung.

Hendriyani, H. \& Tuti Karyani. (2015). Analisis Persepsi dan Sikap Petani Terhadap Lembaga Pembiayaan Formal dan Informal (Suatu Kasus Di Gapoktan Sami Mulya Kec. Sedong, Kabupaten Cirebon, Jawa Barat). Prosiding Seminar Nasional Pembangunan Inklusif di Sektor Pertanian II. Departemen Sosial Ekonomi Pertanian Fakultas Pertanian, Universitas Padjadjaran.

Kasmir. (2004). Bank dan Lembaga Keuangan Lainnya. Jakarta: PT. Raja Grafindo Persada.

Kementerian Koperasi dan Usaha Kecil dan Menengah Republik Indonesia. (2018). Rekapitulasi Data Koperasi per 31 Desember 2016 http://www.depkop.go.id/uploads/la poran/1566783223_Data\%20Koper
asi\%20Tahun\%202016.pdf.

Diakses 29 Oktober 2019.

Kementerian Koperasi dan Usaha Kecil dan Menengah Republik Indonesia. (2018). Rekapitulasi Data Koperasi per 31 Desember 2017. http://www.depkop.go.id/uploads/la poran/1566783253_Data\%20Koper asi\%20Tahun\%202017.pdf.

Diakses 29 Oktober 2019.

Kementerian Koperasi dan Usaha Kecil dan Menengah Republik Indonesia.(2018). Rekapitulasi Data Koperasi per 31 Desember 2018 http://www.depkop.go.id/uploads/la poran/1566783293_Data\%20Koper asi\%20Tahun\%202018.pdf).

Diakses 29 Oktober 2019

Kementerian Pertanian RI. (2017). Statistik Ketenagakerjaan Sektor Pertanian Tahun 2016-2017. Pusat Data dan Sistem Informasi Pertanian Sekretariat Jenderal Kementerian

Pertanian.Kementerian Pertanian RI. (2018). Statistik Ketenagakerjaan Sektor Pertanian Tahun 2017-2018. Pusat Data dan Sistem Informasi Pertanian Sekretariat Jenderal - Kementerian Pertanian.

Kementerian Pertanian. (2019). Rencana strategis direktorat jenderal tanaman pangan tahun 2015-2019. http://tanamanpangan.

pertanian.go.id/assets/front/uploads /document/RENSTRA\%20DITJEN \%20TP\%202015-2019.pdf. Diakses 8 Desember 2019.

Nurhadi. (2013). Lensa Kegiatan Ekonomi SMA/Ma Kelas X. PT. Bumi Aksara - Jakarta.

Otoritas Jasa Keuangan. (2017). Perbankan. diakses pada 1 Desember 2019 melalui https://www.ojk.go.id/id/kanal/perb ankan/Pages/Bank-Umum.aspx. 
Otoritas Jasa Keuangan. (2019). Statistik Perbankan Indonesia. https://www.ojk.go.id/id/kanal/perb ankan/data-dan-statistik/statistikperbankanindonesia/Documents/Pages/Statisti k-Perbankan-Indonesia---

September2019/SPI\%20September\%202019.p df. Diakses 29 Oktober 2019.

Pattern, R.H. \& Rosengard, J.K. (1991). Progress with Profits: The Development of Rural Banking in Indonesia [Working Paper]. San Francisco (AS): International Center for Economic Growth.

Sayaka, B., \& Rivai, R. S. (2011). Peningkatan akses petani terhadap kredit ketahanan pangan dan energi. Bogor (ID): Pusat Sosial Ekonomi dan Kebijakan Pertanian, Kementerian Pertanian.
Tomy, J. (2013). Faktor-faktor yang mempengaruhi produksi usahatani jagung Di Kecamatan Sindue Kabupaten Donggala. Agroland: Jurnal Ilmu-ilmu Pertanian, 20(1), 61-66.

Wahyuni, S. (2003). Kinerja kelompok tani dalam sistem usaha tani padi dan metode pemberdayaannya. Jurnal litbang pertanian, 22(1), 18.

Wiwoho, J. (2014). Peran lembaga keuangan bank dan lembaga keuangan bukan bank dalam memberikan Distribusi keadilan bagi masyarakat. Masalah-Masalah Hukum, 43(1), 87-97. 